\title{
Further studies of the heat island associated with a small midwestern city
}

\author{
Patrick I. Buckley, ${ }^{\dagger}$ Patrick S. Market,* Anthony R. Lupo and Neil Fox \\ Department of Soil, Environmental and Atmospheric Sciences, University of Missouri, Columbia, MO, USA
}

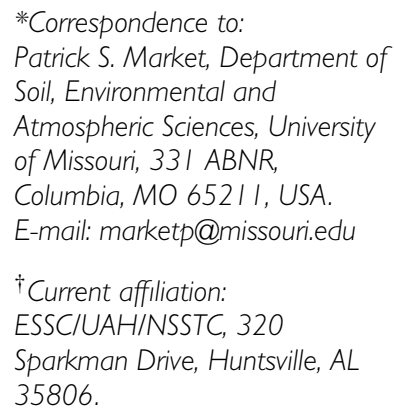

\begin{abstract}
Recently, the University of Missouri (UM) moved its SuomiNet station from the roof of a building near downtown Columbia, Missouri, USA, to the University's rural South Farm. Comparisons of Columbia Regional Airport (KCOU) data and SuomiNet data are presented both prior to and after the latter's relocation. Analysis reveals an elevation of mean temperature by $\sim 1.5^{\circ} \mathrm{C}$ at the downtown location, but no difference between the more rural station and KCOU. These results show that the influence of the Columbia heat island does not extend to $7 \mathrm{~km}$ from the city center and that the present SuomiNet location is now more representative. Copyright $($ C) 2008 Royal Meteorological Society
\end{abstract}

Keywords: urbanization; heat island; SuomiNet

\section{Introduction}

Deforestation and the elimination of green space through urbanization is a well-documented avenue for increasing the magnitude, if not the spatial extent, of urban heat islands (e.g. Changnon, 1981; Pinho and Manso-Orgaz, 2000; Dixon and Mote, 2003; Kim and Baik, 2005). This is true even for small- to mediumsized cities (e.g. Melhuish and Pedder, 1998; Pinho and Manso-Orgaz, 2000; Grathwohl et al., 2006). The heat-island effect is one way in which humans have had discernable and unequivocal impacts on their environment, and accounting for this effect in the global temperature records has been an issue in determining the extent of recent climate change (e.g. Houghton et al., 2001).

Contemporary studies of the heat-island effect have used both traditional methodologies and instrumentation (e.g. Pinho and Manso-Orgaz, 2000; Lupo et al., 2003b), as well as unique methodologies to examine this effect. Melhuish and Pedder (1998) used temperature sensors mounted on a bicycle to determine a cross-section of temperature through Reading, England. Fast et al. (2005) set up a network of temperature dataloggers in Phoenix, but also up the side of the adjacent mountains in order to approximate the vertical profile of the heat-island effect.

Indeed, Lupo et al. (2003b) have documented the magnitude and approximate extent of the heat island for Columbia, Missouri, in the central United States, for which this brief study was also conducted. As such, this work was undertaken to (1) corroborate the work of Lupo et al. (2003b), and (2) assess the change in the extent of the heat-island effect, if any, of a small city undergoing rapid urbanization.

\section{Data and methods}

Temperature data for this study came from two sources. The first was the temperature taken from the hourly surface weather observation from the Columbia Regional Airport (KCOU) in Columbia, Missouri, in the United States (Figure 1). The second source of temperature information came from the sensor affixed to a SuomiNet Global Positioning System (GPS) station. The SuomiNet is a network of GPS antennae which use the wet delay in the transmission of GPS signals to derive measurements of total precipitable water (Businger et al., 1996); each station also has a unit to measure ambient atmospheric temperature, humidity, and pressure (Ware et al., 2000). In each case, the temperatures are measured on the hour, and not an average. Additionally, while each sample includes data for all $24 \mathrm{~h}$ from dozens of days, there was no attempt to stratify by time of the day to determine diurnal variations or influences.

What makes this study unique is that, while the official airport station (KCOU) did not relocate during this study, the SuomiNet station operated by the University of Missouri (UM) was moved. Indeed, it was the relocation of the SuomiNet station that made the study possible. During a move of the UM Atmospheric Science Program facilities in late 2004, the SuomiNet station operated by UM was moved from a rooftop location (with a station identifier of 


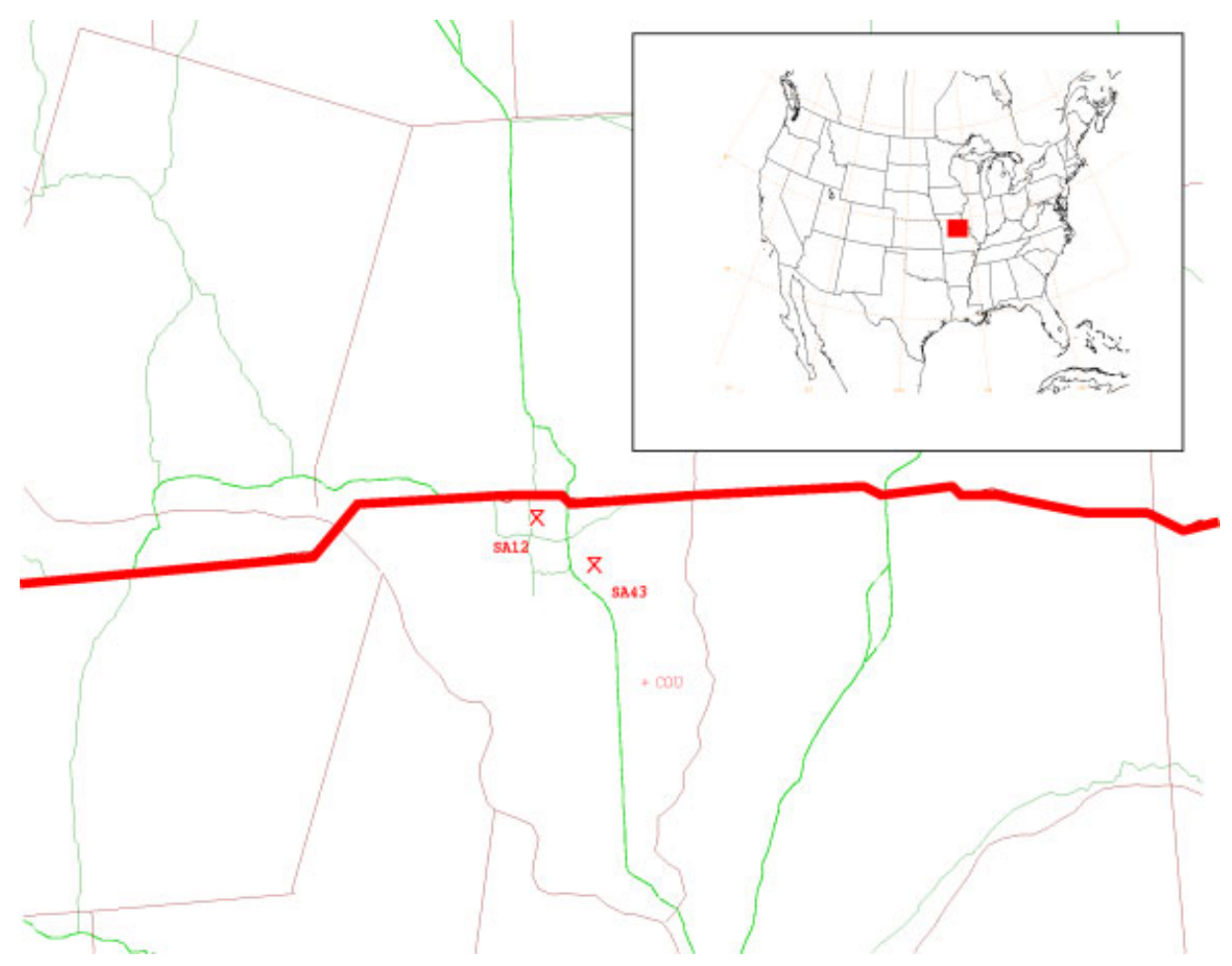

Figure I. Maps of the study area. The larger map shows county borders (thin, brown), major interstate highway (bold, red), and minor highways and city streets (green). The ' + ' marked 'COU' is the location of the Columbia Regional Airport. The closed-top ' $X$ ' symbols marked SAI2 (SA43) are the locations of the SuomiNet station before (after) the December 2004 relocation. The inset is a map of the continental United States, with a red box approximating the larger map of the study area.

'SA 12' at that time) near the city center of Columbia, Missouri (Figure 2(a) and (b)), to a rural location (where the station was then identified as 'SA43'), $\sim 7 \mathrm{~km}$ southeast of the city center (Figure 2(c) and (d)). Locations of the KCOU station, and the UM SuomiNet station before (SA12) and after (SA43) the December 2004 move are all shown in Figure 1.

\section{Analysis}

Temperatures were compared between KCOU and the SuomiNet station both before the move and after. Prior to the move, temperatures in-town at the SuomiNet station were typically warmer than that at KCOU. Figure $3(\mathrm{a})$ is a plot of simultaneous hourly temperatures $(N=1327$ pairs $)$ from KCOU against those from the SuomiNet station during January and February 2004. Note how the data lie consistently above the perfect fit line, showing the frequent elevation of in-town, urban temperatures over the more rural airport temperatures. Indeed, a histogram of these data (Figure 3(b)) shows that the preponderance of temperature differences $\left(T_{\mathrm{KCOU}}-T_{\mathrm{Soumi}}\right)$ was less than zero (cooler in rural areas), with a long tail toward negative differences. The mean temperature difference for January and February 2004 was $-1.6{ }^{\circ} \mathrm{C}$ with a standard deviation of $\pm 1.3^{\circ} \mathrm{C}$. Data $(N=1316$ pairs $)$ from June and July of 2004 revealed a similar elevation of downtown, urban temperatures (Figure 3(c)) as occurred in the winter. This similarity is highlighted by the temperature differences $\left(T_{\mathrm{KCOU}}-T_{\mathrm{Soumi}}\right)$, which also averaged below zero (Figure 3(d)) with a mean temperature difference of $-1.8^{\circ} \mathrm{C}$ and a standard deviation of $\pm 1.4^{\circ} \mathrm{C}$.

After the relocation of the SuomiNet station to the more rural location (Figure 2(c) and (d)) and subsequent renaming to SA43, temperature differences were much less dramatic. We begin again with the winter season of January and February of 2005 (Figure 4(a)) and note a much better distribution than previously of the actual data $(N=1012)$ about the line of perfect fit. The histogram of these data (Figure 4(b)) shows the data on temperature differences normally distributed about zero, without a pronounced tail in either direction. Indeed, the mean difference had shrunk to $-0.0^{\circ} \mathrm{C}$, with a much smaller standard deviation of $\pm 0.7^{\circ} \mathrm{C}$. The data for June and July of $2005(N=$ 1083) show the same improved distribution about the one-to-one fit line (Figure 4(c)), similar to the post-move data from January and February of 2005. While there was a broader distribution about the mean (Figure $4(\mathrm{~d})$ ), with a standard deviation of $\pm 1.1^{\circ} \mathrm{C}$, the mean temperature difference was still reduced to $-0.1^{\circ} \mathrm{C}$.

Statistical testing of these results using a simple Chi-square goodness-of-fit test (e.g. Neter et al., 1988) reveals that the distributions in Figure 3(a) and (d) are normal when the center line and the 0.0 line are shifted in order to align them (not shown). This test was performed by comparing the observed result to a standard normal distribution probability density 
(a)

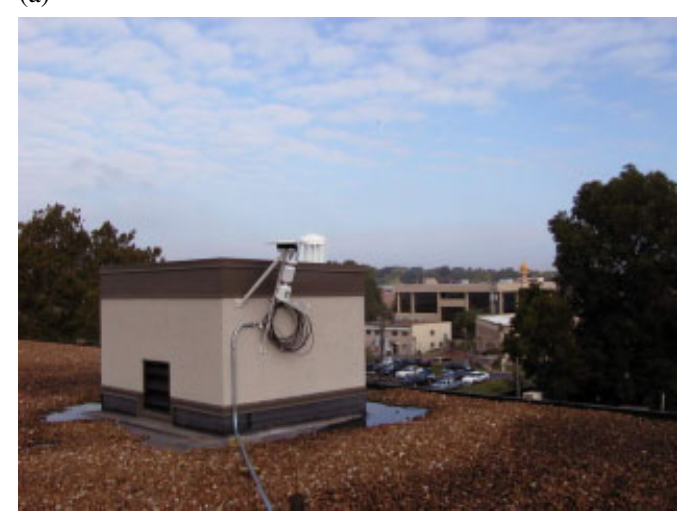

(c)

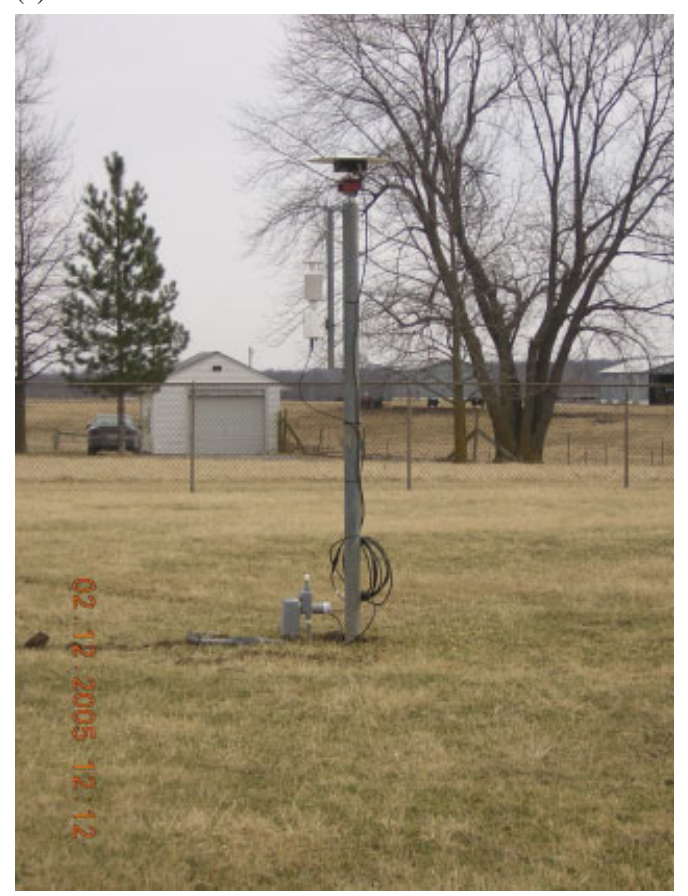

(b)

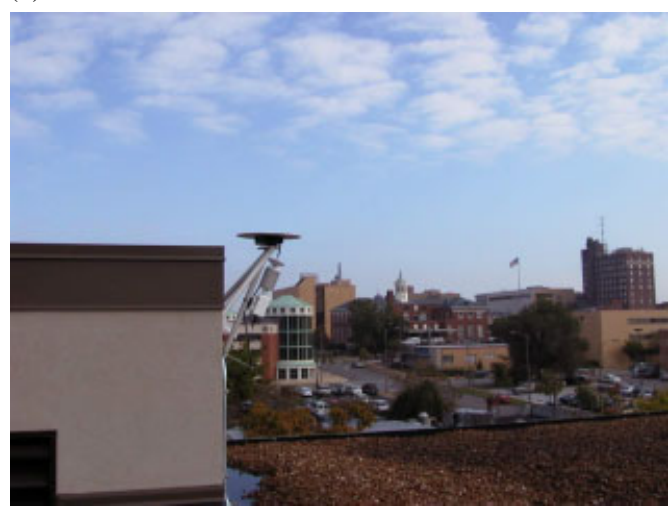

(d)

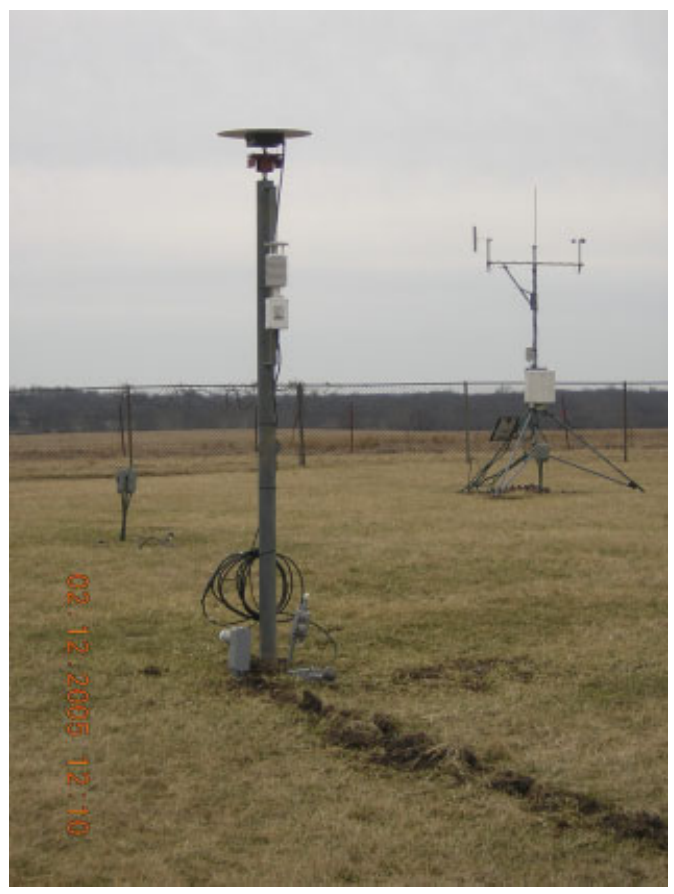

Figure 2. Photographs of the SuomiNet station operated by the University of Missouri both before (SAI2) the December 2004 relocation looking (a) northwest and (b) northeast, and also the SuomiNet station after (SA43) the December 2004 relocation looking (c) east and (d) south.

function and the result is significant at the $95 \%$ confidence level. No such shift was needed in order to match up the distributions in Figure 4 with the standard normal distribution, and these results were significant at the $90 \%$ (Figure 4(a) and (b)), and 95\% (Figure 4(c) and (d)) confidence levels, respectively. These results for Figure 4 are consistent with those found by Lupo et al. (2003a).

Finally, a note on the representativeness of these sampling periods is in order. Both years were classified as ENSO neutral according to the Japanese Meteorological Agency definition (e.g. Lupo et al., 2007 and references therein). More specifically, January-February 2004 was a cool period $\left(-0.8^{\circ} \mathrm{C}\right)$ with close to normal precipitation. January-February 2005 was warmer than normal $\left(+2.2^{\circ} \mathrm{C}\right.$ for the period) and January was quite wet, with $15.1 \mathrm{~cm}$ of precipitation compared to a mean of $4.7 \mathrm{~cm}$ (1890 to present). Temperatures for June-July 2004 were $-1.8^{\circ} \mathrm{C}$, below normal, which were quite cool for the period, and some places in Missouri experienced their third coldest summer on record. However, precipitation totals for the period were close to normal. June-July 2005 was warm $\left(+1.1^{\circ} \mathrm{C}\right.$, above normal) and July was very dry, with $1.6 \mathrm{~cm}$ of precipitation compared to a normal total of $9.0 \mathrm{~cm}$.

\section{Conclusions}

That the temperatures were warmer at an urban weather station than a rural one comes as no surprise. Yet, the results shown here corroborate the findings of Lupo et al. (2003b) that even a city of modest size (Columbia, Missouri, population was $~ 84000$ in 2000) can have a measurable heat island. Indeed, the temperature differences between the urban core and KCOU discovered by Lupo et al. (2003b) of 1.1 to $1.7^{\circ} \mathrm{C}$ compare well with those shown here of 1.6 

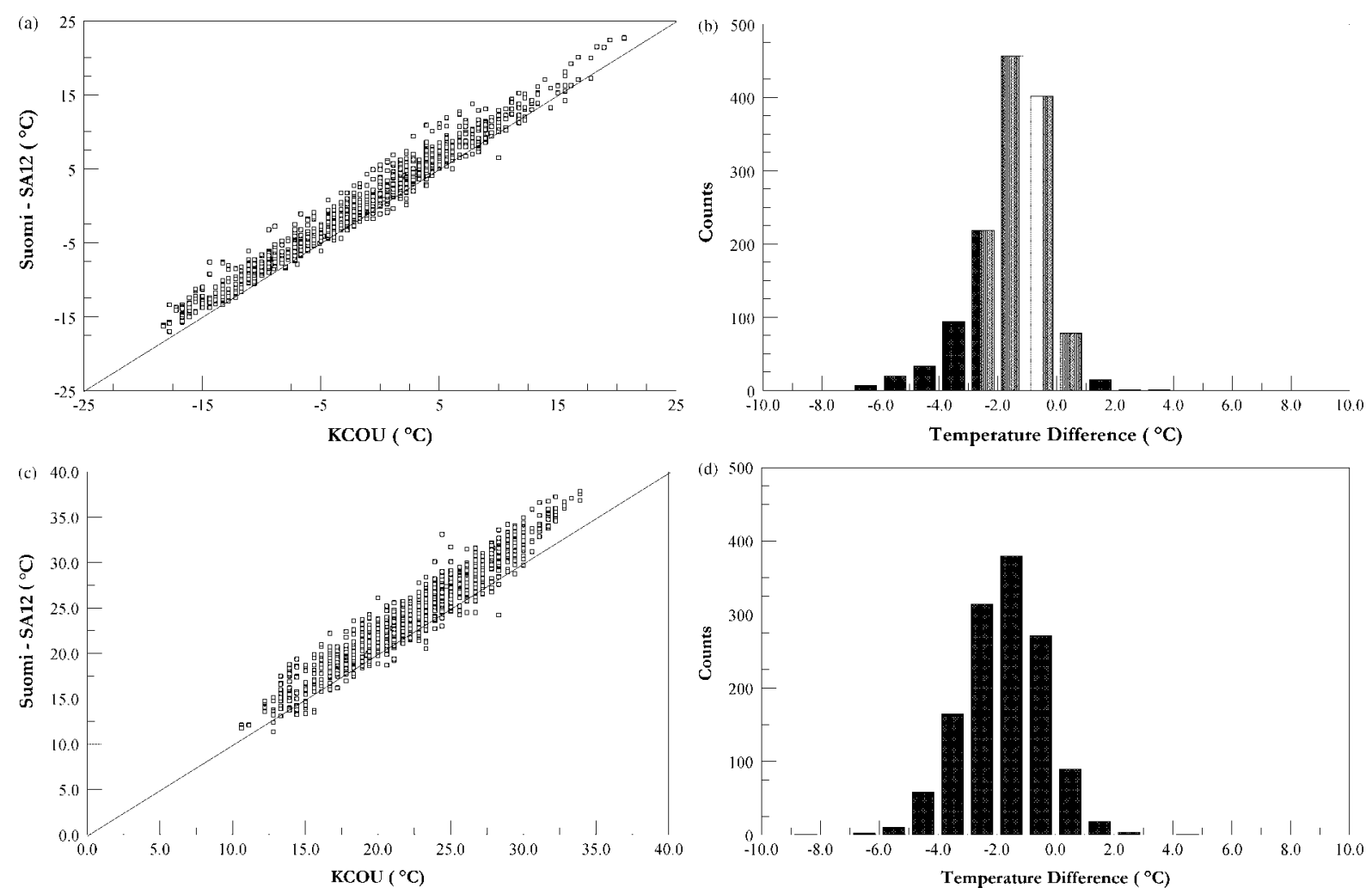

Figure 3. (a) Scatter plot of the temperature at the SuomiNet station (SAI2) against the temperature at the Columbia Regional Airport (KCOU), both in ${ }^{\circ} \mathrm{C}$ for the months of January and February, 2004; (b) a histogram of the temperature differences between $\mathrm{KCOU}$ and SAI 2 (TKCOU-TSoumi) in ${ }^{\circ} \mathrm{C}$ for the months of January and February, 2004; (c) as in (a) above, but for June and July, 2004; (d) as in (b) above, but for June and July, 2004.
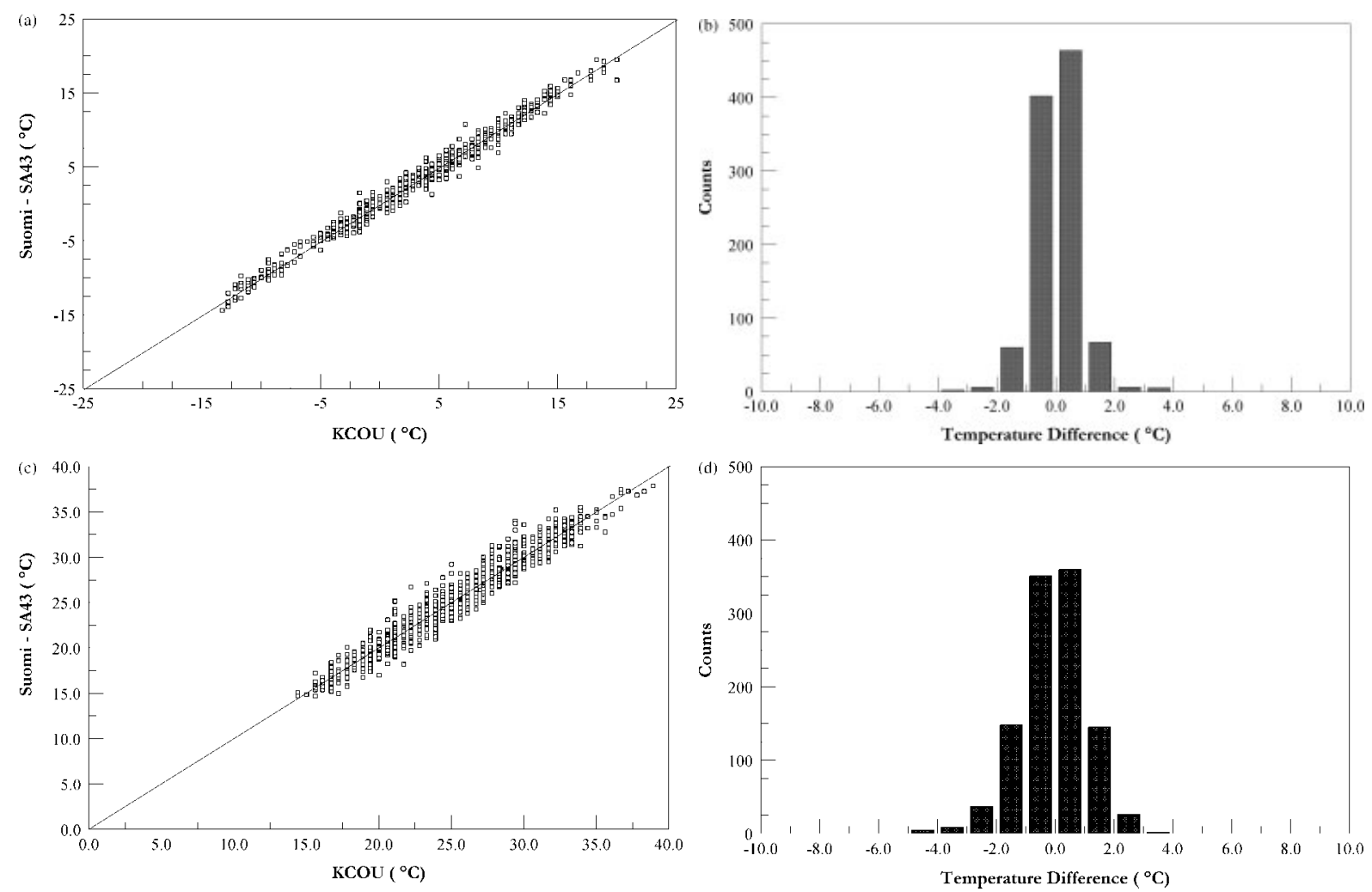

Figure 4. (a) Scatter plot of the temperature at the SuomiNet station (SA43) against the temperature at the Columbia Regional Airport (KCOU), both in ${ }^{\circ} \mathrm{C}$ for the months of January and February, 2005; (b) a histogram of the temperature differences between $\mathrm{KCOU}$ and SA43 (TKCOU-TSoumi) in ${ }^{\circ} \mathrm{C}$ for the months of January and February, 2005; (c) as in (a) above, but for June and July, 2005; (d) as in (b) above, but for June and July, 2005. 
to $1.8^{\circ} \mathrm{C}$. While the values found here are somewhat higher than those found previously, the samples cannot be shown to be significantly different. Therefore, in spite of rapid and ongoing urbanization in and around the Columbia area we can say that, as of the time of this writing, the Columbia heat island does not yet extend to $\sim 7 \mathrm{~km}$ from the city center (at least to the southeast).

Finally, the statistical testing reveals that the manmade impact of the heat-island effect does not alter the distribution of temperatures in any significant way. Rather, the impact is to 'shift' the distribution toward higher values allowing certain climatological thresholds (e.g. number of days above $90^{\circ} \mathrm{F}$ ) to occur more often, or making sure that these are easier to attain.

\section{Acknowledgements}

The authors would like to express their gratitude to the two anonymous reviewers whose comments helped to improve and clarify the manuscript.

\section{References}

Businger S, Chiswell SR, Bevis M, Duan J, Anthes RA, Rocken C, Ware RH, Exner M, VanHove T, Solheim FS. 1996. The promise of GPS in atmospheric monitoring. Bulletin of the American Meteorological Society 77: 5-18.

Changnon SA. 1981. METROMEX: A Review and Summary, Meteorological Monographs No. 40. American Meteorological Society: Boston, MA; 181.

Dixon PG, Mote TL. 2003. Patterns and causes of Atlanta's urban heat island-initiated precipitation. Journal of Applied Meteorology 42: $1273-1284$.

Fast JD, Torcolini JC, Redman R. 2005. Pseudovertical temperature profiles and the urban heat island measured by a temperature datalogger network in Phoenix, Arizona. Journal of Applied Meteorology 44: 3-13.

Grathwohl K, Scheiner S, Brandt L, Lupo AR. 2006. Analysis of weather data collected from two locations in a small urban community. Transactions of the Missouri Academy of Science 40: 50-55.

Houghton JT, Ding Y, Griggs DJ, Noguer M, van der Linden PJ, Dai X, Maskell M, Johnson CA. 2001. Climate Change 2001: The Science of Basis, Contributions of Working Group I to the Third Assessment Report of the Intergovernmental Panel on Climate Change. Cambridge University Press: Cambridge; 881.

Kim YH, Baik JJ. 2005. Spatial and temporal structure of the urban heat island in Seoul. Journal of Applied Meteorology 44: 591-605.

Lupo AR, Kelsey EP, McCoy EA, Halcomb CE, Aldrich E, Allen SN, Akyuz A, Skellenger S, Bieger DG, Wise E, Schmidt D, Edwards M. 2003a. The presentation of temperature information in television broadcasts: What is normal? National Weather Digest 27(4): 53-58.

Lupo AR, Market PS, Akyüz FA, Guinan PE, Lam JE, Oravetz AM, Maune WC. 2003b. The Columbia, Missouri, Heat Island Experiment (COHIX): The influence of a small city on local surface temperature distributions and implications for local forecasts. Electronic Journal of Operational Meteorology 4: 2003-2EJ3, Access via: http://www.nwas.org/ej/pdf/2003-EJ3.pdf.

Lupo AR, Kelsey EP, Weitlich DK, Mokhov II, Akyuz FA, Guinan PE, Woolard JE. 2007. Interannual and interdecadal variability in the predominant Pacific Region SST anomaly patterns and their impact on a local climate. Atmosfera 20: 171-196.

Melhuish E, Pedder M. 1998. Observing an urban heat island by bicycle. Weather 53: 121-128.

Neter J, Wasserman W, Whitmore GA. 1988. Applied Statistics, 3rd edn. Allyn and Bacon Press: Boston, MA.

Pinho OS, Manso-Orgaz MD. 2000. The urban heat island in a small city in coastal Portugal. International Journal of Biometeorology 44: 198-203.

Ware RH, Fulker DW, Stein SA, Anderson DN, Avery SK, Clark RD, Droegemeier KK, Kuettner JP, Minster JB, Sorooshian S. 2000. SuomiNet: A real-time national GPS network for atmospheric research and education. Bulletin of the American Meteorological Society 81: 677-694. 